Rev. Int. Contam. Ambie. 36 (2) 351-359, 2020

DOI: 10.20937/RICA.53054

\title{
BIODEGRADACIÓN DE RESIDUOS DE ACEITE USADO DE COCINA POR HONGOS LIPOLÍTICOS: UN ESTUDIO IN VITRO
}

\author{
Biodegradation of waste used cooking oil by lipolytic fungi: An in vitro study
}

\author{
Marcia M. MOYA-SALAZAR ${ }^{1}$ y Jeel MOYA-SALAZAR ${ }^{2,3 *}$
}

\footnotetext{
${ }^{1}$ Facultad de Farmacia y Bioquímica, Universidad Privada Norbert Wiener. Av. Arequipa 444, Lima 01, 51001 Lima, Perú

${ }^{2}$ Hospital Nacional Docente Madre Niño San Bartolome, Av. Alfonso Ugarte 825, Cercado de Lima 15001, Perú

${ }^{3}$ Facultad de Medicina Humana, Universidad Privada Norbert Wiener, Jr. Larrabue y Unanue 110, Lima 01, Perú.

*Autor para correspondencia: a2018200823@uwiener.edu.pe
}

(Recibido:enero 2018; aceptado mayo 2018)

Palabras clave: aguas residuales, Penicilium, Aspergillus, Amorphoteca, biorremediación

\begin{abstract}
RESUMEN
Los residuos de aceites usados de cocina (RAUC) son uno de los más graves factores de contaminación del agua porque son capaces de crear una capa que dificulta el paso de oxígeno y es difícilmente eliminable. Con el objetivo de demostrar la capacidad y eficiencia de biodegradación in vitro de RAUC mediante hongos lipolíticos se realizó un estudio con tres géneros hongos provenientes de efluentes industriales de aceite de palma (Penicilium, Aspergillus y Amorphoteca). Se evaluó la eficiencia de biodegradación en un contenedor con partes iguales $(300 \mathrm{~mL})$ de RAUC y agua de grifo donde se inocularon $\pm 10^{4}$ conidios $/ \mathrm{mL}$ en los experimentos con un género, $\pm 50^{3}$ conidios $/ \mathrm{mL}$ con dos géneros $\mathrm{y} \pm 33300$ conidios $/ \mathrm{mL}$ con los tres géneros. Para cada experimento se realizaron tres repeticiones y todos fueron incubados a 27 y $30{ }^{\circ} \mathrm{C}$ hasta por ocho días. Los niveles de actividad lipolítica entre géneros de hongos difirieron durante los primeros días del experimento $(\mathrm{p}<0.05)$ normalizándose hacia el octavo día $(\mathrm{p}=0.573)$. La combinación de tres géneros mejoró la eficiencia de biodegradación ( $\mathrm{p}$ $<0.001$ ), comparable con la evaluación a los 8 días de los experimentos individuales $(\mathrm{p}=0.012)$. Todos los experimentos a $27{ }^{\circ} \mathrm{C}$ tuvieron mejor eficiencia que los de $30^{\circ} \mathrm{C}(\mathrm{p}<0.001)$. Los tres hongos lipolíticos tienen alta capacidad y eficiencia de biodegradación de RAUC in vitro luego de ocho días de incubación a $27^{\circ} \mathrm{C}$.
\end{abstract}

Key words: residual water, Penicilium, Amorphoteca, Aspergillus, bioremediation

\begin{abstract}
The waste used cooking oil (WUCO) is one of the most serious factors of water pollution because it is able to create a layer that hinders the passage of oxygen and is difficult to remove. In order to demonstrate the capacity and efficiency of in vitro biodegradation of WUCO by lipolytic fungi, a study was conducted with three genera of fungi from industrial effluents of palm oil (Penicilium, Aspergillus and Amorphoteca). The efficiency of experimental biodegradation was evaluated in a container with equal parts $(300 \mathrm{~mL})$ of WUCO and tap water, where they were inoculated: \pm 104 conidia $/ \mathrm{mL}$
\end{abstract}


for individual experiments, $\pm 50^{3}$ conidia/mL for a dual evaluation (two genera) and $\pm 33300 \mathrm{conidia} / \mathrm{mL}$ for an evaluation of the three fungi. For each experiment three replicates were performed and all were incubated at 27 and $30{ }^{\circ} \mathrm{C}$ for up to eight days. Lipolytic activity levels among genera of fungi were significant during the first days of the experiment $(p<0.05)$, normalizing to eighth day $(p=0.573)$. The combination of the three fungi improved the efficiency of biodegradation $(\mathrm{p}<0.001)$, comparable with the eight-day evaluation of individual experiments $(p=0.012)$. All experiments at $27^{\circ} \mathrm{C}$ had better efficiency $(\mathrm{p}<0.001)$. The three lipolytic fungi have high capacity and efficiency of biodegradation of WUCO in vitro after eight days of incubation at $27^{\circ} \mathrm{C}$.

\section{INTRODUCCIÓN}

Los principales problemas ambientales en el Perú son la contaminación del agua, la erosión del suelo y la deforestación. La contaminación hídrica incluye los residuos industriales, aguas residuales y los residuos relacionados con el petróleo (Carrizales et al. 1999).

Las actividades del ser humano están generando modificaciones del equilibrio hídrico convirtiendo las reservas de agua en peligrosas e impropias para el consumo humano, la agricultura y la pesca, entre otras actividades (Ongley 2004, Moss 2008). Según la Organización Mundial de la Salud, en el Perú entre el 21 y el $25 \%$ de las enfermedades son ocasionadas por cambios en el ambiente, principalmente los relacionados con temperatura, disponibilidad de agua y desertificación (Valdez et al. 2013). Pese a estas condiciones de contaminación del agua, el $86 \%$ del agua dulce es usada actualmente para la agricultura y actividades afines, es por ello que el informe de la Fundación para la Seguridad Ambiental y Sostenibilidad, señaló que en las próximas décadas Perú se enfrentará a una crisis crónica del agua en todo el país, al igual que otros países del mundo (Cosgrove y Rijsberman 2000).

La contaminación por los residuos de aceite usado de cocina (RAUC) es uno de los factores más graves de contaminación del agua, ya que es capaz de crear una capa sobre la superficie del agua que dificulta el paso de oxígeno pudiendo matar a los seres vivos de los ríos, canales o mares. Esta capa es difícil de eliminar, aunque se considera, las más de las veces, con nimiedad (Canakci 2007, Abdul y Bhargavi 2015). El Instituto Nacional de Tecnología Industrial Argentino (INTI) señala que aproximadamente un litro de RAUC puede contaminar hasta mil litros de agua, lo que representa la cantidad de agua que consume aproximadamente una persona promedio durante 11.5 años (Solate y Vargas 2013). Asimismo, las industrias aceiteras han crecido considerablemente en las últimas décadas debido a que obtienen gran variedad de derivados vegetales. No obstante, estas industrias causan problemas cada vez más graves para las poblaciones locales y sus medios de vida pues el proceso de extracción de aceite exige grandes cantidades de agua, que posteriormente son descargadas como desechos directamente a los ríos (Shirkie y Ching 2000). En el Perú, por ejemplo, más de la mitad de los ríos están contaminados (Chillón, Mantaro y Chili, entre otros) en gran parte por productos derivados de plantas aceiteras (Oré et al. 2009).

En numerosos estudios previos se ha reportado la utilidad de los microrganismos capaces de absorber y degradar metabólicamente estos aceites (Okogbenin et al. 2014, Soleimaninanadegani y Manshad 2014). Estos señalan una alta efectividad en la reducción de lípidos/aceites, principalmente de plantas industriales. Sin embargo, se han descrito problemas como la adaptación limitada de los microrganismos en condiciones ambientales locales, su desarrollo experimental únicamente in vitro y la falta de integración entre los organismos que limitan el proceso de biorremediación en desmedro de la salud ambiental global. Los microrganismos con capacidad para degradar aceite son principalmente bacterias y hongos (Nizam 2008), que tienen una mayor eficiencia si se usan de manera combinada a temperaturas óptimas $\left( \pm 30^{\circ} \mathrm{C}\right)$ (Otálora et al. 2000, Bin 2008). Sin embargo, cuando se ha comparado la eficiencia de degradación entre bacterias y hongos usando trioleína, aunque no se determinó diferencia en ambos, hubo mayores reportes de biodegradación para géneros de hongos, principalmente con métodos de asilamiento convencional (agar Sabouraud) y modificados (ácido fosfórico en medio Czapek-Dox) siendo favorables los géneros Aspergillus, Penicillium, Fusarium ( $F$. avenaceum y $F$. solani), entre otros (Otálora et al. 2000, Domínguez 2002, Bin 2008, Rodríguez 2011, Okwoute e Ijah 2014).

En la investigación que se presenta, demostramos la capacidad de biodegradación in vitro de hongos lipolíticos sobre los residuos de aceites usados de cocina, comparando el rendimiento entre géneros 
fúngicos y la turbidez del producto final del agua biodegradada por hongos

\section{MATERIALES Y MÉTODOS}

El estudio se realizó en el Hospital Nacional Docente Madre Niño San Bartolomé, en Lima. Se utilizaron tres hongos con capacidad para degradar aceites (Penicilium sp, Aspergilus sp. y Amorphoteca sp.) obtenidos de efluentes industriales de aceite de palma de la Amazonia del Perú y caracterizados en la Universidad Peruana Cayetano Heredia, en Lima, Perú (Vertiz 2016).

El fundamento de la reacción de biodegradación de RAUC por hongos lipolitícos se muestra en la figura 1. El estudio se dividió en tres etapas: preanalítica, analítica y postanalítica.

\section{A. Etapa preanalítica}

Las cepas identificadas y seleccionadas se inocularon en agar Sabouraund-dextrosa (ASD) (Merck, Darmstadt, Alemania) al $5 \%$, incubándose a $37 \pm$ $1{ }^{\circ} \mathrm{C}$ con $68 \%$ de humedad relativa por $24 \mathrm{~h}$, posterior al aislamiento primario donde se observaron las colonias características de cada hongo inoculado (Okogbenin et al. 2014). Las cepas se crioconservaron a $-20{ }^{\circ} \mathrm{C}$ hasta su transporte y procesamiento.

Los contenedores de plástico se esterilizaron previamente por radiación, en estos se preparó un contenedor de plástico con partes iguales de agua de grifo y RAUC (300 $\mathrm{mL}$ de ambos) para cada experimento (Otálora et al. 2000, Bin 2008). Los RAUC fueron procedentes de grasa usada de frituras (2 papas $($ Solanum tuberosum $)=$ peso aproximado \pm 180 gr $)$ durante $5 \pm 1 \mathrm{~min}$, a intensidad de fuego moderado (Canakci 2007). Primero se inocularon las cepas sobre agua de grifo y luego se mezcló con RAUC, evitando la contaminación de la fase acuosa bajo condiciones de esterilidad (durante la inoculación inicial y en cada observación).

\section{B. Etapa analítica}

Para la obtención de conidios se realizó cultivo con 20 mLASD por 11 días. La evaluación de la viabilidad de los conidios fue mediante la capacidad de formar colonias viables (unidades formadoras de colonia por mililitro, UFC $/ \mathrm{mL}$ ) con siembra en placas (Palmero et al. 2009). Luego de evaluar el crecimiento y desarrollo completo de conidios de cada hongo se procedió a inocular los conidios de Penicilium, Aspergilus y Amorphoteca del medio ASD a la fase acuosa de la matriz de almacenamiento $(300 \mathrm{~mL}$ de agua de grifo y $300 \mathrm{~mL}$ de RAUC). La mezcla se realizó por lateralización para un mejor desprendimiento y disolución de los hongos lipolíticos (APHA 2014). Antes de la mezcla de RAUC con agua, se separaron las impurezas y los artefactos propios de las frituras con una espátula. Para la inoculación se realizó una suspensión de conidios en suero salino fisiológico. Para los experimentos individuales fue de \pm 100000 conidios $/ \mathrm{mL}$. Se inoculó una vez por cada género en cada uno de los tres experimentos. Para los experimentos de actividad lipolítica combinada, se inocularon \pm 50000 conidios $/ \mathrm{mL}$ de cada género para la evaluación dual, y \pm 33300 conidios/ mL para la evaluación de las tres cepas de los géneros fúngicos en conjunto. En general, se inoculó $1 \mathrm{~mL}$ de suspensión de suero fisiológico (con conidios $/ \mathrm{mL}$ ) en la mezcla de agua del grifo y RAUC $(600 \mathrm{ml}$ volumen total).

Se realizaron tres repeticiones de cada experimento para cada género y para los experimentos combinados (entre dos y tres géneros). Todos los experimentos se condujeron a $27 \pm 1^{\circ} \mathrm{C}$ (temperatura ambiente) y $30 \pm 1{ }^{\circ} \mathrm{C}$ (incubación por convección) de los cultivos de hongos en medio líquido (agua/ RAUC). Para realizar la evaluación de turbidez entre los inóculos de la fase acuosa se utilizó el patrón 0.5 de turbidez de McFarland en turbidímetro PCE-TUM 20 (PCE, Albacete, España) (McFarland 1907). Se consideró esta evaluación para el crecimiento de bacterias ambientales contaminantes durante el tiempo de incubación $(\leq 8$ días). Las mezclas se agitaron solamente al inicio de cada experimento, por tanto, se evitó la formación de microgotas de RAUC durante esta evaluación.

Asimismo, las colonias se mantuvieron en tubos tapa rosca estériles, en condiciones de refrigeración en ASD hasta su identificación definitiva mediante técnicas moleculares. La identificación se realizó

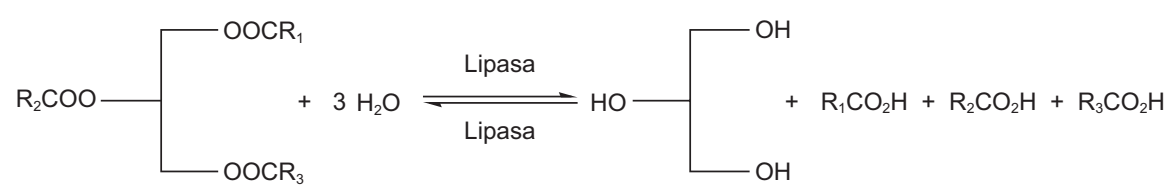

Fig. 1. Reacción general reversible catalizada por la lipasa en medio natural 
por microscopía con la técnica de microcultivo en lámina desde ASD y determinación molecular (Vertiz 2016). La extracción de ADN fúngico se hizo con CTAB2 (bromuro de hexadeciltrimetilamonio: Sigma-Aldrich, St. Louis, Missouri, EUA) (Murray y Thompson 1980, Alwakeel 2013), purificados con el equipo QIA quick PCR Purification (QiaGen, Hilden, Alemania). Los cebadores fueron: nuSSU-0817-59 (TTAGCATGGAATAATRRAATAGGA); nu-SSU-1196-1139 (TCTGGACCTGGTG AGTTTCC), ynu-SSU-1536-1539 (ATTGCAATGCYCTATCCCCA) ya que estos se unen a secuencias de la subunidad pequeña de $\mathrm{ADN}$ ribosomal (ADNr) de los hongos representativos de todos los grupos filogenéticos (Murray y Thompson 1980, Borneman y Hartin 2000). Treinta y cinco ciclos de reacción en cadena de la polimerasa (PCR) se realizaron a 94 ${ }^{\circ} \mathrm{C}$ durante $0 \mathrm{~s}, 56{ }^{\circ} \mathrm{C}$ durante $10 \mathrm{~s}$, y $72{ }^{\circ} \mathrm{C}$ durante $30 \mathrm{~s}$, seguido de $72^{\circ} \mathrm{C}$ durante $2 \mathrm{~min}$. Por último, las secuencias conservadas dentro de este grupo se identificaron con al servicio de Genetics Computer Group Inc. (University of South Florida, Tampa, FL) (Datos no mostrados).

\section{Etapa postanalítica}

Se observó la biodegradación de RAUC diariamente, mediante fotografiado seriado durante ocho días, luego se realizó la medición de la concentración de aceites y grasas totales libres en el producto final, mediante la cuantificación de ácidos grasos libres por el método de espectrofometría de masas-cromatografía de gases (GCMS) en el laboratorio de cromatografía del grupo Societé Genérale de Surveillance (SGS) del Perú (Okwoute y Ijah 2014). Se centrifugaron cada uno de los contenidos de cada experimento a $3500 \mathrm{rpm} \times 3 \mathrm{~min}$., separándose el sobrenadante para este análisis. Con esto se evaluó la eficiencia de la biodegradación de RAUC mediante la prueba de degradación en medio liquido con control de crecimiento sobre RAUC (Okogbenin et al. 2014).

\section{Análisis de datos}

Para la evaluación de los ensayos de eficiencia de la biodegradación de RAUC se utilizó el análisis de varianza (Andeva) de una vía tomando como variable categórica los géneros de hongos y, como variable de respuesta, la medición de la biodegradación de RAUC: concentración de ácidos grasos en la suspensión, medidos por cromatografía de gases-espectrometría de masas (GCMS). Se utilizó la prueba de t para muestras independientes para la comparación entre la eficiencia de degradación a 27 y $30^{\circ} \mathrm{C}$ de los cultivos de hongos en medio líquido. El nivel de significación fue de $0.05(\alpha=0.05)$. El análisis de datos se realizó con el analizador estadístico IBM SPSS v.20.0 (Armonk, EUA) y MS-excel (Redmond, EUA) para Windows.

\section{RESULTADOS}

En principio, en la identificación microscópica de los hongos se obtuvieron similitudes con otras especies de los géneros Penicillium, Aspergillus y Amorphoteca, todos comparados en el laboratorio (datos no mostrados). En la identificación molecular coincidieron todos los géneros de los hongos lipolíticos (especies no identificadas) (Vertiz 2016). El control diario de la biodegradación de RAUC se muestra en la figura 2.

Encontramos diferencias significativas entre las temperaturas de los ensayos de biodegradación de RAUC,
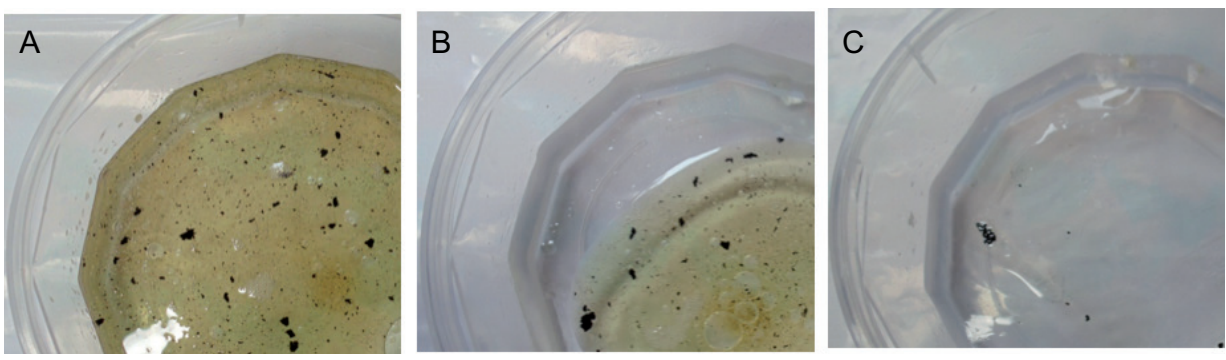

Fig. 2. Biodegradación de residuos de aceites usados de cocina (RAUC) in vitro por acción combinada de Penicillium, Aspergillus y Amorphoteca. A. Evaluación de la eficiencia biodegradativa el día dos ( $85 \pm 2 \%$ de ácidos grasos libres aproximadamente). B. Evaluación de biodegradación de RAUC durante el día cuatro ( $44 \pm 2 \%$ de ácidos grasos libres aproximadamente). C. Biodegradación completa al día ocho, mediante combinación de hongos lipolíticos. ( $8 \pm$ $2 \%$ de ácidos grasos libres aproximadamente) 
BIODEGRADACIÓN FÚNGICA DE ACEITE USADO DE COCINA

CUADRO I. BIODEGRADACIÓN DE RAUC A $27^{\circ} \mathrm{C}$ y $30^{\circ} \mathrm{C}$. EVALUACIÓN DE ACTIVIDAD LIPOLÍTICA Y ÁCIDOS GRASOS LIBRES DURANTE LOS OCHO DÍAS DEL EXPERIMENTO.

\begin{tabular}{|c|c|c|c|c|c|c|c|c|}
\hline & \multicolumn{4}{|c|}{ Actividad lipolítica $27^{\circ} \mathrm{C}$} & \multicolumn{4}{|c|}{ Actividad lipolítica $30^{\circ} \mathrm{C}$} \\
\hline & 3 días & 5 días & 8 días & $\mathrm{p}$ valor** & 3 días & 5 días & 8 días & $\mathrm{p}$ valor $* *$ \\
\hline Penicillium (Género 1) & $21 \pm 1.11$ & $55 \pm 0.13$ & $96 \pm 1.25$ & $<0.02$ & $18 \pm 1.21$ & $54 \pm 2.73$ & $93 \pm 2.88$ & $<0.002$ \\
\hline Aspergillus (Género 2) & $33 \pm 0.98$ & $70 \pm 0.89$ & $98 \pm 0.41$ & $<0.001$ & $22 \pm 2.51$ & $68 \pm 1.23$ & $97 \pm 0.33$ & 0.041 \\
\hline Amorphoteca (Género 3) & $19 \pm 2.73$ & $44 \pm 1.02$ & $95 \pm 3.12$ & 0.001 & $18 \pm 3.42$ & $41 \pm 2.44$ & $95 \pm 0.45$ & 0.003 \\
\hline
\end{tabular}

*Los valores señalados para cada género fúngico como porcentajes de actividad lipolítica son inversamente proporcionales al porcentaje de ácidos grasos libres en el contenedor (agua/RAUC). **Los p-valores evalúan la diferencia entre los días tres y ocho de cada género respecto al proceso de biodegradación.

teniendo mayor eficiencia a $27^{\circ} \mathrm{C}\left(\mathrm{t}_{322.87}=15.047\right.$, $\mathrm{p}<0.001)$. No encontramos diferencia significativa entre cada ensayo de biodegradación, tanto en los ensayos individuales $(p=0.229)$ como en los ensayos de actividad lipolítica combinada $(\mathrm{p}=0.109)$. Como resultado de la eficiencia de biodegradación de RAUC, no se encontraron diferencias significativas en la prueba individual $(\mathrm{p}>0.750)$, variando de la interacción con dos y tres géneros [género1 vs. género $2(p=0.027)$, género1 vs. género3 $(p=0.002), y$ género2 vs. género3: $(\mathrm{p}=0.001)]$. La combinación de tres géneros mejoró la eficiencia de biodegradación $(\mathrm{p}<0.001)$, comparable con la evaluación a los ocho días de los experimentos individuales $(\mathrm{p}=0.012)$. Los niveles de actividad lipolítica entre géneros de hongos fueron significativos durante los primeros días del experimento $(\mathrm{p}<0.05)$ y a diferentes temperaturas $\left(27^{\circ} \mathrm{C}\right.$ y $\left.30^{\circ} \mathrm{C}\right)$ (Cuadro I).

La evaluación de actividad lipolítica combinada demostró que el uso de dos géneros y tres géneros de hongos, independientemente del genero fúngico, permitió una biodegradación promedio de

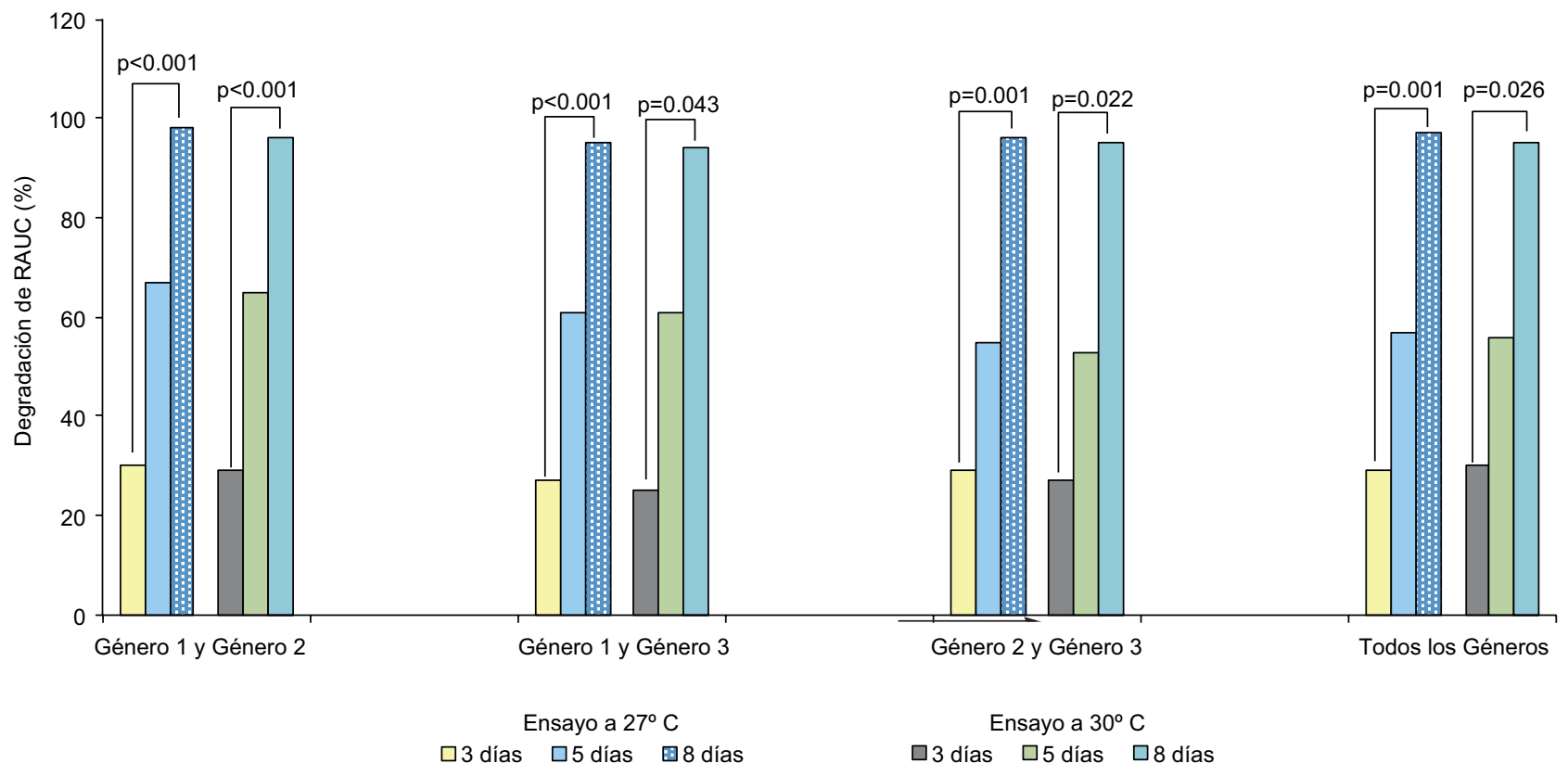

Fig. 3. Actividad lipolítica combinada de dos géneros y tres géneros de hongos a $27{ }^{\circ} \mathrm{C}$ y $30^{\circ} \mathrm{C}$. Promedio de biodegradación de los residuos de aceites usados de cocina (RAUC) $95.7 \pm 1.3 \%$ (rango: 94-98\%). Los $p$-valores evalúan la diferencia entre los días tres y ocho de cada género respecto al proceso de biodegradación. No se encontraron diferencias significativas entre los productos de biodegradación finales de 2 y 3 géneros $(\mathrm{p}$ valor $=0.120)$. Los valores señalados para cada especie fúngica como porcentajes de actividad lipolítica son inversamente proporcionales al porcentaje de ácidos grasos libres en el contenedor (agua/ RAUC). Abreviaturas: Género 1: Penicillium; Género 2: Aspergillus.; Género 3: Amorphoteca 
$95.5 \%$ de RAUC. En la figura 3 se observan los niveles de actividad lipolítica entre los días de evaluación, mostrando resultados significativos en la evaluación de dos géneros y entre los tres géneros (ambos con $\mathrm{p}<0.05$ ) a diferentes temperaturas de análisis, pero obteniéndose mejores resultados a $27{ }^{\circ} \mathrm{C}(\mathrm{p}=0.045)$. Estos valores se normalizaron significativamente hacia el último día del experimento $(\mathrm{p}=0.573)$.

Encontramos diferencias significativas de descontaminación bacteriana en agua post-biodegradación y el estándar de turbidez $(\mathrm{p}<0.001)$, es decir la evaluación final de la mezcla presentó niveles por debajo del estándar de turbidez. Entonces, este análisis es una medida indirecta de contaminación del medio por turbidez.

\section{DISCUSIÓN}

La capacidad de biodegradación de RAUC en los tres géneros estudiados tuvo gran eficiencia in vitro luego de ocho días de incubación, teniendo un rendimiento comparable entre los experimentos de géneros combinados y los experimentos de géneros individuales, siendo más óptimos a $27^{\circ} \mathrm{C}$. Asimismo, las aguas post-biodegradación mostraron baja turbidez por contaminación bacteriana durante los ensayos.

Durante el tiempo en estudio, no se han hallado estudio sobre biodegradación de RAUC con hongos con características lipolíticas. Los RAUC contaminan las fuentes de agua para consumo de muchos pobladores, primordialmente de comunidades rurales-agrícolas, e impactan directamente en los recursos hidrobiológicos, los cuales también son parte del sustento directo de estas personas. Del mismo modo, los RAUC son producidos cada vez con mayor cuantía por los centros de comida rápida donde, y por normativas nacionales e internacionales, los aceites usados son cambiados cada cinco y/o siete horas posteriores al uso, consignando, importantes fuentes de contaminación del agua por RAUC (Mba et al., 2015).

Nuestros hallazgos demostraron que todos los géneros fúngicos lipolíticos produjeron incrementos de concentración de ácidos grasos libres en medio líquido en diferentes niveles (Cuadro I y Fig. 2), estas concentraciones fueron superiores al porcentaje mínimo reportado previamente $(20 \%)$ y a otros reportes en sustratos similares (Oso 1978, Negedu et al. 2012). Estos ácidos libres fueron directamente proporcionales al grado de biodegradación de RAUC.
Recientemente demostramos que los ácidos grasos contaminantes pueden unirse a las lipasas fúngicas (Moya-Salazar et al. 2019). Al igual que en reportes previos, nuestros resultados muestran alta capacidad biodegradativa de Aspergillus, Penicillium y Amorphoteca bajo las condiciones controladas del estudio (Otálora et al. 2000, Rodríguez 2011, Negedu et al. 2012, Vertiz 2016). Si bien evidenciamos diferencias significativas intra e inter géneros, los resultados finales demostraron biodegradación de RAUC $\geq 94 \%$. Esto indica una alta capacidad de degradación de estos géneros fúngicos sobre los RAUC con niveles de actividad lipolítica gradual.

La actividad incrementada de lipasas fúngicas se atribuye a la actividad de lipasas extracelulares que evidencian la oxidación de los triglicéridos (El Azzabi et al. 1981, Ogugua y Chukwuma 2011, Okwoute y Ijah 2014). Las diferencias de actividad lipolítica, y por consiguiente, biodegradación de RAUC, están atribuidas a la capacidad de producción de lipasas y a la especificidad de utilización de ácidos grasos libres por cada género fúngico. Esto explicaría lo sucedido en este estudio: cuando se utilizaron los tres géneros combinados se obtuvo mayor eficiencia en la biodegradación de RAUC.

Como estudios previos demostraron, los géneros que permitieron óptimos resultados de biodegradación fueron, en este orden, Aspergillus, Penicillium y Amorphoteca (Cuadro I) (El Azzabi et al. 1981, Otálora et al. 2000, Rodríguez 2011, Negedu et al. 2012).

De la misma forma, el estudio in vitro permitió demostrar la capacidad de biodegradación de géneros fúngicos durante ochos días de evaluación bajo condiciones físicas controladas. Dada la naturaleza del estudio, no podemos aseverar que estas aguas post-biodegradación sean aptas para consumo el humano ya que difícilmente se podrían eliminar todos los contaminantes. Sin embargo, se podrían derivar sus usos de acuerdo con las necesidades de los usuarios (regadío, etc.) en función de su calidad. Cuando analizamos la turbidez de los productos finales de biodegradación encontramos diferencias significativas de contaminación por microrganismos ( $\mathrm{p}<0.001)$, es decir, si bien bajo nuestros protocolos de trabajo no se desarrollaron contaminantes bacterianos, sí hallamos otros contaminantes que pudieran afectar la calidad del agua post-biodegradación (Fig. 2C). En ese sentido, proponemos otros posibles métodos de eliminación de ácidos grasos del contenedor líquido (agua/RAUC) asociado al proceso de bioremediacion fúngica, por ejemplo a través de la filtración o el uso de minerales que permitan incrementar el proceso de biodegradación presentado en este estudio (El-Masry et al. 2004). 
Sin embargo, la alta producción de lipasas extracelulares podría ocasionar la inhibición de cepas fúngicas, ya que al generarse progresivamente este efecto en el medio acuoso quedaría probablemente exento de hongos. Esta factible situación permitiría usos más seguros del agua post-lipolización fúngica en diversas áreas de la industria y a contrario sensu la inhibición ocasionaría disminución en la cantidad disponible mínima que pueda cumplir la función biorremediadora de RAUC. Dado que este estudio centró su análisis en la capacidad y eficiencia biodegradativa de RAUC por hongos, no es posible considerar estas variables dentro del análisis final de los resultados. Se necesitan futuras investigaciones que evalúen estas características.

Véase ahora la evolución de los conocimientos relacionados con la biodegradación de aceites. Aunque, con anterioridad, se han descrito, evaluado y comparado microrganismos con capacidad de biodegradación (Shirkie y Ching 2000), no se han desarrollado procesos circunspectos sobre biorremediación de RAUC, y como se ha mencionado, sí se han desarrollado han presentado dificultades para su empleo cosmopolita en las comunidades.

Nuestros resultados demuestran la efectividad de microorganismos solos o combinados. Sin embargo, este estudio in vitro requiere posteriores evaluaciones que permitan estudiar otros factores como las variables del crecimiento fúngico de las cepas utilizadas en los puntos de cultivo intermedios o finales. También, debe de evaluarse la saturación de oxígeno en cada punto de evaluación de los experimentos, para saber de buena tinta si después de la lipólisis se permite el paso de oxígeno a través de la capa de grasa. Asimismo, se debe ejercer control en la producción y evaluación externa de conidios, y determinar la producción de micotoxinas para establecer su posible rol en la actividad lipolítica global.

La contaminación del agua es un problema mundial trascendental que requiere una continua evaluación y revisión de las políticas de recursos hídricos en todos los niveles. Los problemas de contaminación del agua se dan tanto más en países de altos ingresos como en países de bajos ingresos donde se generan problemas ambientales y de salud (Avcievala 1991, Bereciartua 2005).

Hemos descrito un método sencillo que proporciona resultados de remediación natural (biodegradación), método que espera contribuir en la descontaminación (biorremediación) del agua (alcantarillado, ríos, riachuelos, etc.) mediante el uso de hongos con actividad lipolítica.

\section{CONCLUSIÓN}

Este estudio demostró la capacidad y eficiencia de biodegradación in vitro de residuos de aceites usados de cocina por los tres géneros fúngicos utilizados (Penicilium, Aspergillus y Amorphoteca) luego de ocho días de incubación a $27^{\circ} \mathrm{C}$. Ya sea en combinación de géneros o de manera aislada, estos hongos permitieron obtener agua con bajo nivel de turbidez por contaminación bacteriana.

\section{REFERENCIAS}

Abdul R.M. y Bhargavi R. (2015). Biodiesel production from waste cooking oil. J. Chem. Pharm. Res. 7 (12), 670-681.

Alwakeel S.S. (2013). Molecular identification of isolated fungi from stored apples in Riyadh, Saudi Arabia. Saudi J. Biol. Sci. 20 (4), 311-317. DOI: $10.1016 /$ j.sjbs.2013.05.002

APHA (2014). Compendium of methods for the microbiological examination of foods, Lipolytic Microorganisms. American Public Health Association, Washington D.C., EUA, 87 pp.

Avcievala S. (1991). The nature of water pollution in developing countries. Natural Resources Series No. 26. UNDTCD, United Nations, Nueva York, EUA, 22 pp.

Beltrán R.C. (1991). Influencia del procesamiento sobre la calidad final del aceite. Rev. Palmas. 12, 102-107.

Bereciartua P.J. (2005). Vulnerability to global environmental changes in Argentina: opportunities for upgrading regional water resources management strategies. Water Sci. Technol. 51 (5), 97-103.

Bin H.B. (2008). Bioremediation of oil contaminated wastewater using mixed culture. Tesis de Licenciatura. Faculty of Chemical Natural and Resources Engineering. Faculty of Chemical and Natural Resources Engineering, Universiti Malaysia Pahang. Pekan, Malaysia, $78 \mathrm{pp}$.

Borneman J. y Hartin R.J. (2000). PCR Primers that amplify fungal rRNA genes from environmental samples. Appl. Environ. Microbiol. 66 (10), 4356-60.

Canakci M. (2007). The potential of restaurants waste lipids as biodiesel feedstocks. Bioresource Techn. 98 (1), 183-190. DOI: 10.1016/j.biortech.2005.11.022

Carrizales L., Batres L., Ortiz M.D., Mejía J., Yáñez L., García E., Reyes H.H. y Díaz-Barriga F. (1999). Efectos en salud asociados con la exposición a residuos peligrosos. Scientiae Naturae 2, 5-28.

Cosgrove W. y Rijsberman FR. (2000). World Water Vision: Making Water Everybody's Business, World 
Water Council. Earths can Publications Ltd., London, Inglaterra.

Domínguez P. (2002). Influencia de las condiciones de fermentación en la obtención de lipasas de Candida rugosa, y en su actividad y en su enantioselectividad frente a reacciones orgánicas no convencionales. Tesis de Postgrado. Departamento de Química Orgánica y Farmacéutica, Universidad Complutense de Madrid. Madrid, España, 58 pp.

El Azzabi T.S., Clarke J.H. y Hil S.T. (1981). Lipolytic activity of fungi on rapeseed oil. J. Sci. Food Agric. 32, 493-497. DOI: 10.1002/jsfa.2740320512

El-Masry M.H., El-Bestawy E. y El-Adl N.I. (2004). Bioremediation of vegetable oil and grease from polluted wastewater using a sand biofilm system. World J. Microbiol. Biotechnol. 20 (6), 551-557. DOI: 10.1023/B:WIBI.0000043162.17813.17

Mba O.I., Dumont M. y Ngadi M. (2015). Palm oil: Procesing, characterization and utilization in the food industry - A review. Food Biosc. 2015; 10: 26-41.

DOI: 10.1016/j.fbio.2015.01.003

McFarland J. (1907). The nephelometer: an instrument for estimating the number of bacteria in suspensions used for calculating the opsonic index and for vaccines. J. Am. Med. Assoc. 49 (14), 1176-78.

Moss B. (2008). Water pollution by agriculture. Philos. Trans. R. Soc. London [Biol]. 363 (1491), 659-66. DOI: $10.1098 /$ rstb.2007.2176

Murray M. y Thompson W. (1980). Rapid isolation of high molecular weight plant DNA. Nucleic Acids Res. 8 (19), 4321-4326.

Moya-Salazar J., Vértiz-Osores J., Jibaja S., AcevedoEspindola C., Rupa R., Alarcón-Díaz M., et al. (2019). Fungi lipases homology modeling and molecular docking with fatty acids and tripalmitin of palm oil effluent. Arc Org Inorg Chem Sci. 4(1):25-35.

DOI: 10.32474/AOICS.2019.04.000182

Negedu A., Ameh J.B., Umoh V.J. y Atawodi S.E. (2012). Lipolytic activity of some fungal species on castor oil. AJFAND 12 (6), 6686-99.

Nizam M. (2008). Bioremediation of oil from domestic wastewater using mixed culture: effect of inoculum concentration an agitation speed. Tesis de Postgrado. Faculty of Chemical Natural \& Resources Engineering. University Malaysia Pahang. Pekan, Malaysia, $55 \mathrm{pp}$.

Ogugua N.C. y Chukwuma O.J. (2011). Isolation of lipase producing fungi from palm oil mil efffuent (POME) dumps sites al Nsukka. Braz. Arch. Biol. Technol. 54 (1), 113-6.

DOI: $10.1590 / \mathrm{S} 1516-89132011000100015$

Okogbenin O.B., Anisiobi G.E., Okogbenin E.A., Okunwaye T. y Ojieabu A. (2014). Microbiological as- sessment and physiochemical parameters of palm oil mill effluent collected in a local mill in Ovia North East area of Edo State, Nigeria. Herald J. Microbiol. Biotech. 1 (1), 1-9.

Okwoute L. y Ijah J.J. (2014). Bioremediation of palm oil mill effluent (POME) polluted soil using microorganisms found in organic wastes. Int. J. Biotechnol. 3 (3), 32-46.

Ongley E.D. (2004). Control of water pollution from agriculture. FAO Irrigation and drainage paper. Food and Agriculture Organization of the United Nations, Roma, Italia, $101 \mathrm{pp}$.

Oré M.T., Castillo L., Van Orsell S. y Vos J. (2009) El agua frente a Nuevos Desafíos. Actores e iniciativas en Ecuador, Perú y Bolivia. Instituto de Estudios Peruanos, Lima, Perú, 466 pp.

Oso B.A. (1978). The lipase activity of Talaromyces emersoni. Cana. J. Bot. 56 (16), 1840-43.

Otálora M.F., Peña J.L., Martínez M.M. y Varela A. (2000). Evaluation of the oil degradation capacity of lipolytic bacteria in the residual sludge of the oil palm extraction. PALMAS 21 (1), 283-92.

Palmero D., Iglesias C. y Tello J.C. (2009). Estudio preliminar de la germinación y viabilidad de las especies de Fusarium en respuesta al potencial osmótico del medio. [en línea].https://www.researchgate.net/ publication/235898061_Estudio_preliminar_de_la_ germinacion_y_viabilidad_de_las_especies_de_Fusarium_en_respuesta_al_potencial_osmotico_del_medio $27 / 03 / 18$

Rodríguez Z.P. (2011). Aislamiento e identificación de cepas microbianas como potenciales agentes para biorremediación de efluentes en una extractora de palma aceitera. Tesis de postgrado. Escuela de Ciencia Químicas, Facultad de Ciencias, Escuela Superior Politécnicas de Chimborazo. Chimborazo, Ecuador, $78 \mathrm{pp}$.

Shirkie R. y Ching J. (2000). Aceite en el Agua. Contaminación por palma de aceite en Malasia. [en línea]. https://idl-bnc-idrc.dspacedirect.org/bitstream/handle $/ 10625 / 23277 / 110732$.pdf? sequence $=1$ 28/03/18

Solate N. y Vargas M. (2013). Diseño de estrategias de recolección del aceite de cocina usado para su reutilización en la producción de Biodisel en cuatro (4) barrios de la ciudad de Cali. Tesis. Departamento de Ciencias Administrativas , Facultad Ciencias Económicas y Administrativas, Universidad autónoma del Occidente. Santiago de Cali, Colombia, 140 pp.

Soleimaninanadegani M. y Manshad S. (2014). Enhancement of biodegradation of palm oil mill effluents by local isolated microorganisms. IntSch. Res. Notices. Article ID 727049, 8 pp. DOI: $10.1155 / 2014 / 727049$ 
Valdez H.W., Napanga S.E., Oyola G.A., Mariños A.J., Vílchez G.A., Medina O.J. y Berto G.M. (2013). Análisis de situación de salud del Perú. Ministerio de Salud, Dirección General de Epidemiología. Ministerio de Salud del Perú, Lima, Perú, 136 pp.
Vertiz O.J. (2016). Especies fúngicas biodegradadores de residuos de aceite de palma (Elaeis guineensis) procedentes de efluentes industriales. Tesis de Maestría. Facultad de Ciencias y Filosofía, Maestría en Microbiología, Universidad Peruana Cayetano Heredia. Lima, Perú, 89 pp. 